\title{
Language learning experience of two Vietnamese language adult learners
}

\author{
Cao Thi Hong Phuong* \\ Faculty of English \\ Hanoi National University of Education, Vietnam. \\ *Corresponding author \\ Email: hongphuongct@hnue.edu.vn
}

\begin{abstract}
In-depth research on Second Language Acquisition (SLA) has shed light on different factors affecting learners' process of learning an additional language (AL). The well-researched factors may include age, interlinguistic influences, language aptitude, cognition, motivation, and so forth. This case study report compares two adult learners' language learning experiences from social and cognitive SLA perspectives. The key findings reveal that both of the learners mostly relied on three significant factors such as motivation, learners' identity and inter-linguistic influences to acquire the language. From the findings, the paper then suggests some pedagogical implications to maximize the effectiveness of English classroom practices.
\end{abstract}

Keywords: language learning, adult learners, motivation, learners' identity, inter- linguistic influences

$\begin{array}{llll}\text { Received: } & \text { Revised: } & \text { Accepted: } & \text { Published: } \\ \text { 2 May 2018 } & \text { 21 July 2018 } & \text { 30 August 2018 } & \text { 31 August 2018 }\end{array}$

\section{INTRODUCTION}

Second Language Acquisition (SLA) studies have shed light on various factors affecting learners' process of learning an additional language (AL). Different well-researched factors may include age, inter-linguistic influences, language aptitude, motivation, learner identity and so forth. However, little research has been done on SLA with adult language learners in EFL (foreign language learning) contexts (Ross-Feldman, 2003), where learners have few opportunities to communicate with each other beyond classrooms. As RossFeldman (2003) further stated, the complexities of adult English instruction as a second language (L2) or EFL make research in this domain challenging. Exploring issues of affected factors and tracking learners' progress are demanding tasks as they are inter related by diverse factors. Understanding about learners' achievements in light of the research-informed knowledge of SLA can be beneficial to practitioners and learners because the findings may apply to their contexts. Thus, this study offers educators and language teachers modest suggestions for more effectiveness of EFL settings. 


\section{Participants and Contexts}

This report provides a holistic description of language learning experiences of two Vietnamese learners. First, the paper briefly describes the two participants, Nguyen and Tran (pseudonyms) examined in this case study. Nguyen is a 33-year-old army officer from Vietnam who had been learning English since January 2017. He mostly studied by himself via the internet and other English applications such as Rosetta Stone. Nguyen used English in his job mainly to communicate with his military co-workers from European countries through emails. Apart from Vietnamese, he can speak other two languages namely Russian and French; however, his French is more fluent than his Russian. He had lived in Paris for three years and claimed to be a CEFR B2 user of French.

The second participant is Tran, a medical doctor in his early 30s, working in the International Administration Department of a Vietnamese medical university. He had learned English for 20 years, mostly through the explicit instruction of English grammar through the audio-lingual method employed by his teachers. However, he claimed to remember nothing from the formal instruction except simple utterances of greetings and saying goodbyes. During his tertiary education, Tran learned speaking and listening skills in two academic years. At present, Tran uses English for daily communication with his students from Asian countries. Tran claimed to have acquired a CEFR B1 in English according to RELC placement test results. He spent time studying English through BBC channels.

Both of the participants are native speakers of the Vietnamese language. At the time of the interview, they had been in Singapore for two months attending an English communication skills course delivered to Vietnamese civil officers.

\section{METHOD}

This study was conducted as a case study research. The data were collected and analyzed by semi-structured interviews from the participants: Nguyen and Tran, who have been attending an English course in Singapore for two months. The interviews were conducted in English, which was then transcribed and coded and themes emerged. This study employed a qualitative analysis, which is driven by theoretical research and analytic phenomena in a range of possible areas. Creswell (2007) argued that case studies investigate a phenomenon within a bounded system or real-life contexts. The focus is put on the case itself and frequently starts with narrative description, presenting a thematic analysis and ends with implications of what has been learned (Oxford, 2016). Merriam (1988) also stated the interview is one of the primary sources to obtain qualitative data from participants. The interviews were conducted individually with participants to gain an in-depth insight into the subjects' experience of learning an $\mathrm{AL}$ 


\section{RESULTS AND DISCUSSION}

\section{The Discussion of the Key Findings}

In this section, the paper discusses the key findings drawing on the interviews with two participants. Three themes emerged including learners' motivation, learners' identity and the influence of inter-linguistic features, which will be discussed in the light of relevant SLA literature.

\section{Learners' motivation}

Learners' motivation seems to be an important contributing factor to the success of language learning. Ortega (2014) stated that foreign language motivation refers to the learners' desire to initiate L2 learning and the effort they make to pursue it.

This can be observed in the following statement made by Nguyen, who is highly motivated to learn English.

"I learn English because of my job requirement to communicate with my counterparts from the UN peacekeeping office. I want to get B2 to be accepted into a Ph.D. program in Australia".

Nguyen is extrinsically motivated to learn English in order "to achieve some instrumental end" (Ellis, 2015, p.49). External factors such as his job requirements, willingness to achieve B2 and getting accepted into a course, which is considered as extrinsic motivation, were claimed to have contributed significantly to his achievement in learning English. This confirmed the findings in Li's (2006) cognitive approach which had discovered that external factors such as grades, rewards or approval from others are essential in motivating learners to study an AL.

Further conversations with Nguyen revealed that he was intrinsically motivated :

"I decided to learn English for my travel purposes to communicate with local people and explore local cultures. I am interested in participating in United Nation's training courses to improve my knowledge and have more friends in the world".

Nguyen's motivational factors such as traveling purposes, exploration of local cultures, the interest in attending courses and making friends, which were derived from the inner inside his mind, are considered as intrinsic motivation. This also confirmed the findings in Li's (2006), which indicates that motivation stemming from inside the learners themselves are intrinsic oriented. From Nguyen's statement, we can see that he was personally motivated to make his decision to learn English for travel purposes and his interest in taking part in a training course by the UN, which had facilitated him to be actively engaged in learning English in order to master it.

The analysis of Nguyen's data has shown that his motivation displays a hybrid of extrinsic and intrinsic factors such as his job requirement (extrinsic), willingness to achieve B2 and desire to explore the culture (intrinsic). These 
motivations are aligned with Dörnyei's (2009) study of self-determination theory, which involves intrinsic, extrinsic motivations. In other words, the case of Nguyen implies that there is not a clear-cut distinction between the two types of extrinsic and intrinsic motivation in Nguyen's case, but it is highly disparate (Oxford, 1999) and integrated into his self-determined motivation. Both factors attribute to his betterment of learning English.

Tran's case displays a strongly extrinsic motive throughout the interview:

"I wanted to learn English because I could get into a good university, so after finishing, I could get a good job... Also because my job requires me to speak with the students from Asian countries, if I cannot communicate them, my job cannot be fulfilled."

Tran's experience reflects an extrinsic motivation, with evidence of his desire for his academic excellence, job requirement and career opportunities, which is in line with Williams and Burden's framework of motivation mentioned in Dörnyei (1998). The author concluded that external influences on the learners such as rewards, competition, societal expectations and attitude lead to learners' success of L2 learning. Tran's motivational factors may also be interpreted as a cognitive and emotional status of the arousal, leading to a conscious decision to act, which gives rise to a sustained intellectual and substantial period of a continuous effort to achieve his goal.

In sum, analyzing Nguyen's learning experiences regarding "selfdetermination theory," both intrinsic and extrinsic factors played an essential part in his progress in learning English. However, Tran's motivation was mostly influenced by external factors, driving to his decision making, engaging in his L2 learning and seeking learning opportunities (Oxford, 1999). These factors may be ascribed to Tran's improvement in learning English.

\section{Learners' Identity}

Learner' identity, which is originated from learning experiences and academic performance, may direct either competent or problematic behaviors in learning an L2 (Wigfield \& Wagner, 2007). This can be inferred that how one perceives oneself may have both positive and negative impacts on their L2 learning.

The conversations with Nguyen and Tran revealed that they both wish to become fluent English users. For example, Nguyen said:

"I hope to become a fluent English speaker, but I want to speak to be understood as a Vietnamese person who speaks English. English is just a language of communication. I also need to learn about cultures."

Nguyen mentioned that although he encountered obstacles in pronunciation, he wished to improve his English to become a Vietnamese, as opposed to American or British, who could function efficiently in English for communicative purposes. Nguyen's identity shows a substantial alignment with Norton's view of social identity, L2 use and L2 learning mentioned in Ellis (2015), which emphasizes the significance of ownership of the language being learned and rejects the notion of native-likeness or nonnative-likeness. 
Nguyen's ownership of learning English is also congruent with Widdowson (1994), who asserted that if English serves the as a means of international communication; it, therefore, must belong to those who use this language.

On the contrary, Tran confessed that:

"I want to speak English as British speakers because of British English as considered as standardized English. I listen to BBC programmes every day".

Tran's statement indicates that he wished to identify himself as a competent English user to adequately communicate with others like British. It means that Tran's L2 learning experiences may help shape the images of himself as a competent English user (Csizér \& Kormos, 2009). His desire to speak English with a British accent has reflected an identity of Ideal L2 Self mentioned in Badrkoohi \& Maftoon (2017), which demonstrates learners' ideal image of whom they prefer to become. In other words, ideal L2 self helps create possible L2-speaking images for learners to become highly motivated to learn a language. Therefore, it represents L2 specific perspectives that leaners wish to accomplish regarding the results of learning this language (Kim \& Kim, 2014). Thus, these images may have a role to play in contributing to the learners' achievement. Relating to Tran's case, his being ideal himself as an English user of a British accent may be the specific goal for him to achieve. It, therefore, may play an essential role in Tran's success of learning English.

In short, Nguyen has shown an established sense of ownership of the language he has learned. On the other hand, Tran is reflected as ideal L2 self as proficient English user who speaks English with a British accent. Both the images they have created, the efforts they have put to attain their goals may be contributing factors to the success of their learning English. As suggested by Dörnyei \& Chan (2013) learners' ideal selves vivid images and efforts are likely to help learners achieve their aims of becoming proficient L2 users.

\section{Inter-linguistic influences}

One of the most central themes in SLA research is that of the influences of inter-linguistic features, which refers to the various ways in which a specific language can affect other languages within an individual speaker. Typically, it involves two languages that can affect one another in bilingual speakers. The interviews with Nguyen and Tran revealed that inter-linguistic features had strongly impacted their progress in learning English.

The analysis of Tran's data has shown that his inter-linguistic influence of his L1, which is well-researched in the literature as language transfer (Odlin, 2001; Ellis, 2015). This can be observed in his statement that reflects the influences of Vietnamese linguistic structure and pronunciation on his use of L2.

"I very like my teacher in RELC because she focuses on pronunciation,"

"I think that pronunciation is difficult." 
The reasons why he spoke "I very like," because he relied on the Vietnamese language, which is "Tôi rất thich" (equivalent to me very like) to express his opinions. When he uttered "I think," he did not correctly pronounce the voiceless sound " $\theta$," because " $\theta$ " sound does not occur in the Vietnamese language. The phonemic language distance mentioned in Ellis (2015) means that there are no similarities between individual sounds and suprasegmental in the mother tongue and L2 (Nation, 2013). Therefore, Tran relied on his Vietnamese pronunciation of the word "think." In short, there was an influence of Vietnamese structures and pronunciation in the way Tran produced his English, which may not necessarily be accurate. However, it does not cause a communication breakdown, which helps him, to some extent, communicate successfully.

However, Nguyen's case has shown another picture of how he relied on the linguistic resource of his L3, as opposed to L1 (Vietnamese) to learn L4. For example, he said:

"Learning English is not facile [French], ah ... not easy, especially pronunciation."

Interestingly, he claimed that whenever he had obstacles in expressing in English, he attempted to use French to help him convey his meanings in English. This is evidenced in the transcript above where he paused after using the word 'facile' [French, his L3] rather than 'de dang' [Vietnamese, L1], as a prompt for him to say 'easy.' In fact, he showed full awareness of the similar linguistic cognates that French and English share, which to a large extent had helped him learn English vocabulary in particular.

"English and French have similarities in the vocabulary; I always remember the meanings of the English words when I compare with French."

Although he is exceptionally fluent in his L1 (Vietnamese), he significantly relied on his B2 level of French to learn English, which revealed that how Nguyen's being multilingual can support him to acquire an AL. His multilingual ability confirmed the findings in Cook's (1991) study of multicompetence users, which refers to the knowledge of various languages in a person's mind and functions as an elaboration of an established network in people' brain. Therefore, Nguyen's case can be considered as a unique multilingual individual, rather than an individual having attached another language to their repertoire. Hence, his reliance on L3, as a result of his multicompetence, can help him learn L4. Thus, Nguyen's case showed that the influences of somewhat proficient of L3, which share the cognates with L4, can be contributing factors to the progressiveness of L4.

Overall, both participants' progress of learning an AL had influenced a range of inter-linguistic features of their predominant languages. In other words, the inter-linguistic influences played a contributing factor in the improvement in learning English of these two successful language learners. 


\section{Pedagogical implications and recommendations}

Drawing on the discussions, the paper attempts to propose some pedagogical recommendation for EFL contexts to make the instruction more in line with the ultimate goals and underlying rationales for L2 acquisition.

Regarding teaching, language teachers should be better aware of research informed findings in SLA as well as better understanding of learners' prior language learning experience. In turn, this will allow curriculum is making by language teachers to cater to learners' needs of learning a second or foreign language. First, instruction should consider the learners' readiness. If teachers consider the connection between the development of explicit grammar knowledge and the eventual reestablishment of unconscious linguistic systems to afford the point in learners' interlanguage, then formal grammar instruction is of ultimate use (Larsen-Freeman, 2001). Second, early stage instruction, such as in the case of Tran, should give roles for formulaic units as a communicative vehicle for students' L2 acquisition journey. Third, instruction should be embedded in meaning-oriented tasks and activities that give immediate affordances for learners' practice and use (Larsen-Freeman, 2001). If teachers overemphasized on one aspect, neglecting the other, the trade-off effects in learners' language development might occur. The study of Wes by Schmidt (1983) and three Portuguese and Pakistani learners by Ellis (1992) show that lack of balance between formulaic expressions and formal form-focused instruction leads to the limited language development regarding producing the target-like negative (Ellis, 2015). Teachers should also consider implementing task-based language teaching (TBLT) as a teaching approach for adult learners since this approach allows learners to encounter real-world tasks, which not only develop learners' communicative competence (e.g., Ellis, 2003; Nunan, 2004; Willis \& Willis, 2011) but also focus on form. As TBLT has also been acknowledged as one approach that is line with and informed by SLA findings on developmental sequences and processes in interlanguage development (Long, 2016). Therefore, language acquisition can occur through the input that the performances of tasks provide (Ellis \& Shintani, 2014).

In relation to language learning, students should also need to seek learning opportunities beyond classroom settings to add more learning values to their language learning achievement. Both participants mentioned explicitly in the interviews that they self-accessed online sources because they are helpful for them to improve vocabulary and pronunciation as well as other linguistic aspects. From this reflection, it is also significant for language learners to become autonomous and strategic in order to achieve their language learning goals. The case of learners in Ma's (2017) study, for example, show that learners employed different strategies to learn English. The author found that learners used cognitive processing involving metacognition, cognition and self-regulation strategies such as goal setting for L2, reading e-news, practicing speaking and listening through mass media. This, in turn, adds more value to learners' language performance. 
Cao, EduLite: Journal of English Education, Literature, and Culture Vol.3, No.2, August 2018, 101-109 DOI: http://dx.doi.org/10.30659/e.3.2.101-109

\section{CONCLUSION}

The study unveils some characteristics of participants' L2 identity, motivation and inter-linguistic features that account for factors affecting their language learning achievement of two adult learners. Although Nguyen's and Tran's experiences cannot be generalized beyond the context of this study, they have, to some extent, confirmed the congruency between decisive factors in SLA such as learners' motivation, learners' identity and inter-linguistic influences which affect learners' success of learning an AL. This paper can also be referred by language teachers and researchers who advocate communicative competence as the ultimate purpose of language instruction. As the study reveals, language learning improvement results from different factors taking into account the learners' characteristics (e.g., motivation, inter-linguistic features, learning styles/strategies, learners' identity, strategic knowledge) and their conscious personal choice regarding what and how to learn. Classroom practice may serve as a vehicle or catalyst to push learners or to guide them to pursue their own language learning journey.

\section{REFERENCES}

Badrkoohi, A., \& Maftoon, P. (2017). Individual differences and L2 motivation: The case of EFL Learners. International Journal of Applied Linguistics and English Literature, 6(3),

199. https://doi.org/10.7575/aiac.ijalel.v.6n.3p.199

Csizér, K., \& Kormos, J. (2009). Learning experiences, selves and motivated learning behavior: A comparative analysis of structural models for Hungarian secondary and university learners of English. Motivation, language identity, and the L2 self, 98-119.

Cook, V. J. (1991). The poverty-of-the-stimulus argument and multicompetence. Interlanguage studies bulletin (Utrecht), 7(2), 103-117.

Creswell, J. (2007). Research design: Qualitative, quantitative, and mixed methods approach. Sage publications.

Dörnyei, Z. (1998). Motivation in second and foreign language learning. Language Teaching, 31(03), 1-17. https://doi.org/10.1017/S026144480001315X

Dörnyei, Z. (2009). The L2 motivational self-system. Motivation, language identity, and the L2 self, 36(3), 9-11.

Dörnyei, Z., \& Chan, L. (2013). Motivation and Vision: An Analysis of Future L2 Self Images, Sensory Styles, and Imagery Capacity Across Two Target Languages: Motivation and Vision. Language Learning, 63(3), 437-462. https://doi.org/10.1111/lang.12005

Ellis, R. (1992). Learning to communicate in the classroom. Studies in second language acquisition, 14(1), 1-23.

Ellis, R. (2003). Task-based language learning and teaching. OUP.

Ellis, R. (2005). Instructed second language acquisition: A literature review. Wellington: Research Division, Ministry of Education. 
Ellis, R. (2015). Understanding Second Language Acquisition 2nd Edition. OUP.

Ellis, R., \& Shintani, N. (2014). Exploring language pedagogy through second language acquisition research. Routledge.

Kim, T.-Y., \& Kim, Y.-K. (2014). A structural model for perceptual learning styles, the ideal L2 self, motivated behavior, and English proficiency. System, 46, 14-27. https://doi.org/10.1016/j.system.2014.07.007

Larsen-Freeman, D. (2001). Teaching Grammar. In Teaching English as a Second Language (3rd ed.). USA: Heinle \& Heinle.

Li, D. (2006). Motivation in Second Language Acquisition in Chinese Research Students in the UK. Evaluation and Research in Education, 19, 38-58.

Long, M. H. (2016). In Defense of Tasks and TBLT: Nonissues and Real Issues. Annual Review of Applied Linguistics, 36, 5-33. https://doi.org/10.1017/S0267190515000057

Ma, Q. (2017). A multi-case study of university students' language-learning experience mediated by mobile technologies: a socio-cultural perspective. computer-assisted language learning, 30(3-4), 183-203.

Merriam, S. B. (1998). Qualitative Research and Case Study Applications in Education. Revised and Expanded from" Case Study Research in Education.". Jossey-Bass Publishers, 350 Sansome St, San Francisco, CA 94104.

Nation, I. S. P. (2013). Learning vocabulary in another language. New York: CUP.

Nunan, D. (2004). Task-based language teaching. Cambridge, UK: CUP.

Odlin, T. (2001). Language Transfer: Cross-linguistic influence in language learning (pp. 27-167).

Ortega, L. (2014). Understanding second language acquisition. London: Routledge.

Oxford, R. L. (Ed.). (1999). Language learning motivation: Pathways to the new century. Honolulu, Hawaii: Second Language Teaching \& Curriculum Center.

Oxford, R. L. (2016). Teaching and researching language learning strategies: self-regulation in context (Second edition). London: Routledge, Taylor \& Francis Group.

Schmidt, R. (1983). Interaction, acculturation, and the acquisition of communicative competence: A case study of an adult. Sociolinguistics and language acquisition, 137-174.

Ross-Feldman, L. (2003). Second Language Acquisition in Adults: From Research to Practice.

Widdowson, H. G. (1994). The Ownership of English. TESOL Quarterly, 28(2), 33-77. https://doi.org/10.2307/3587438

Wigfield, A. \& Wagner, A. L. (2007). Competence, motivation, and identity development during adolescence. In A. J. Elliot \& C. S. Dweck (Eds.), Handbook of competence and motivation. (pp. 222-39). New York: The Guilford Press

Willis, D., \& Willis, J. (2011). Doing task-based teaching. Oxford: OUP. 